\title{
Solvent Effect and Adsorption Study of Mild Steel Protection from Acid Corrosion Using Eco-friendly Formulations of Annatto Extract
}

\author{
Ekemini Ituen $^{a, b, *}$ and I. S. Umoren ${ }^{b}$ \\ ${ }^{a}$ Research Scholar, Materials Physics and Chemistry Research Laboratory, China University of \\ Petroleum, Qindao, China \\ ${ }^{b}$ Department of Chemistry, Faculty of Science, University of Uyo, Nigeria
}

Received September 26, 2015; accepted October 15, 2016

\begin{abstract}
Annatto extract (dye) was investigated as a cheap and ecologically friendly alternative corrosion inhibitor. The corrosion process was monitored with mild steel coupons in 1.0 $\mathrm{M}$ hydrochloric acid at temperatures between $30{ }^{\circ} \mathrm{C}$ to $90{ }^{\circ} \mathrm{C}$ by weight loss and spectroscopic techniques. The dye effectively inhibited the corrosion of mild steel in the acid at the studied temperatures. Inhibition efficiency obtained was found to vary with temperature and concentration of the dye. Adsorption models were used to predict the nature of the dye-steel surface interaction. Thermodynamic models provided evidence of spontaneous physical and chemical adsorption mechanism with the evolution of heat. Kinetic studies revealed a deepening effect on the activation potential in the presence of the dye. The effect of solvent and synergistic intensifiers on the effectiveness of the dye was also assessed. Heavy metal ion composition in the formulation was determined and was within the limit of environmental and health safety.
\end{abstract}

Keywords: adsorption, annatto, corrosion inhibitor formulation, inhibition effectiveness, intensifier, solvents.

\section{Introduction}

Corrosion is a phenomenon that is perhaps as old as when humans started using metallic structural materials. Failure of materials as well as high cost and toxicity usually associated with the importation of corrosion control chemicals might have been some of the driving forces for active research on cheap and efficient techniques of combating corrosion, the simplest being the use of corrosion inhibitors. Little wonder why a wide range of materials have been tested and reported as efficient corrosion inhibitors [1-2]. Some of these substances reported or currently used for corrosion control are very expensive and toxic. Economically, an inhibitor produced from cheap and readily available materials would be more desirable. On the other hand, non-toxicity to the environment in

\footnotetext{
*Corresponding author. E-mail address: ebituen@gmail.com
} 
terms of heavy metal composition and biodegradability is also desired. Materials that best fit into these descriptions are locally sourced materials such as plant products. Some plants, including those used for food production, have been reported to possess good inhibitive properties against corrosion of different metals under different conditions [3-21]. When farmers prefer to sell their produce at higher profits to industries for manufacture of corrosion inhibitors instead of food production, food scarcity is inevitable. The paradigm has now shifted to the use of agricultural wastes and wild (non-edible) plants. In Nigeria, for instance, the transformation of local materials into products useful for industrial application (like corrosion inhibitors), within acceptable limits of health and environmental safety, will keep an open door to the actualization of 2010 Nigerian content act.

Annatto (Bixa orellana L.) is a fruiting shrub that grows generously up to 5-10 m high as a wild plant in southern Nigeria. Some are cultivated by individuals for the purpose of either folk medicine or dye extraction from the seeds (which are covered with reddish aril (Figs. 1-2)). Phytochemical screening of this extract has revealed the presence of tannins, saponins, flavonoids, terpenoids, phenolics, anthraquinones, steroids, proteins and carbohydrates with no alkaloids [22].

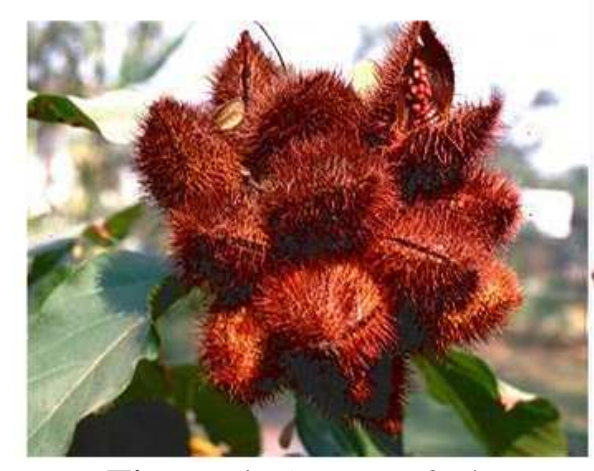

Figure 1. Annatto fruits.

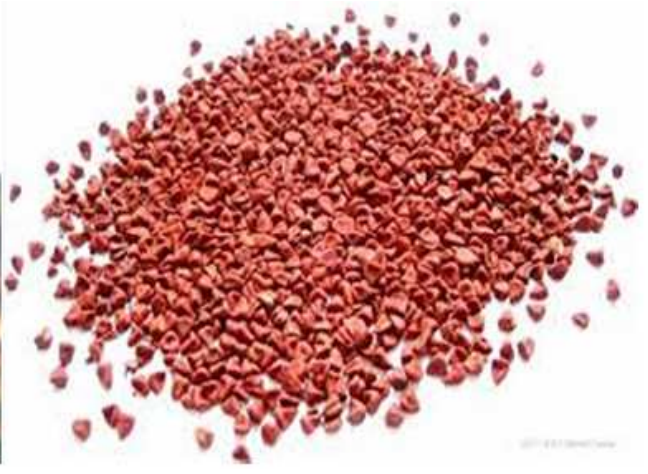

Figure 2. Annatto seeds.

Bixin and norbixin carotenoids (structures in Fig. 3) have been isolated from the dye extract, but bixin is claimed to be the predominant colouring compound in the extract [23-24].

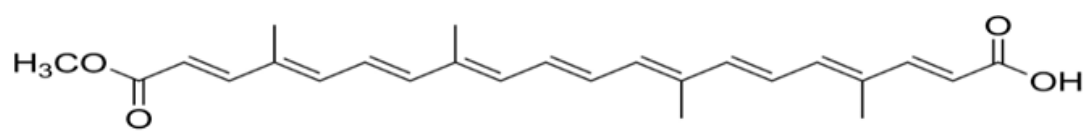

(a)

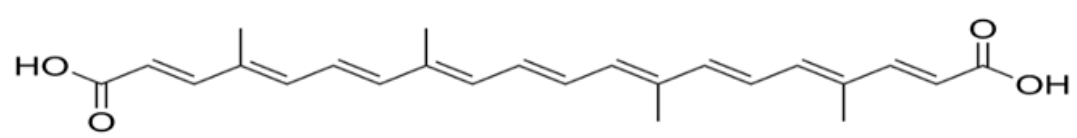

(b)

Figure 3. Molecular structures of (a) bixin and (b) norbixin.

The dye has been locally used in the manufacture of hair oil, shoe polish, floor polishes, nail gloss, furniture lacquer, domestic lipsticks, etc. The paste may also be used as a natural dye for cloth and hair, and is sometimes employed in paint industries [25]. Extracts from the fruits and seeds of the plant have been used in 
folk medicine as additives for treatment of malaria, fever, astringent, kidney diseases and skin diseases, because of its anti-bacterial and anti-microbial activity [25-26]. The dye is also used as colourant in some foods and beverages, due to its characteristic colour (see Figs. 2-3). Some reports have claimed that some synthetic dyes can inhibit metal corrosion [27-29]. Some of these dyes offer good corrosion protection to the metal, but are toxic or expensive. The present study aims to investigate annatto dye, a natural dye from a cheap, nontoxic and renewable source, as a possible replacement to these synthetic dyes used in corrosion inhibitors. It also investigates the effect of solvents on its anticorrosive effectiveness.

\section{Materials and method \\ Materials preparation}

Mild steel sheets (thickness $=0.46 \mathrm{~mm}$ ), with the composition (wt. \%) $0.13 \mathrm{C}$, $0.18 \mathrm{Si}, 0.39 \mathrm{Mn}, 0.60 \mathrm{P}, 0.04 \mathrm{~S}, 0.025 \mathrm{Cu}$, and balance $\mathrm{Fe}$ ), were mechanically press-cut into $4.0 \mathrm{~cm} \times 4.0 \mathrm{~cm}$ pieces, degreased in absolute ethanol, washed first in water then in acetone, air-dried at room temperature, and stored in a moisture free desiccator to be used for the study. Fresh Bixa orellana seeds were harvested from a local forest in between Ikot Ambon village in Ibesikpo-Asutan L.G.A. of Akwa Ibom State, Nigeria. They were air-dried, grounded, and extracted in ethanol using standard procedures reported elsewhere [18]. Different concentrations of the dye extracts $(1.0,3.0$ and $5.0 \mathrm{mg} / \mathrm{L})$ were prepared as test solutions. The corrosive agent was general purpose grade $\mathrm{HCl}$, prepared to a concentration of $1.0 \mathrm{M}$ in double de-ionized water.

\section{Weight loss technique}

Pre-weighed mild steel coupons were totally immersed in the test solutions containing the acid, in the presence and absence of the dye, retrieved after 5 hours immersion time, washed thoroughly in $20 \% \mathrm{NaOH}$ solution containing $200 \mathrm{~g} / \mathrm{L}$ of zinc dust, rinsed in water, dried in acetone, and re-weighed using a FA2104A digital weighing balance with $\pm 0.0001 \mathrm{~g}$ sensitivity. This was conducted at temperatures $30-60{ }^{\circ} \mathrm{C}$ in triplicates, and the values of mass losses were used to estimate the corrosion rate using equation 1:

$$
C R=\left(w_{1}-w_{2}\right) / A t
$$

where $C R\left(\mathrm{gcm}^{-2} \mathrm{~h}^{-1}\right)$ is the corrosion rate, $w_{1}$ and $w_{2}(\mathrm{~g})$ are the weights before and after immersion, respectively, $A\left(\mathrm{~cm}^{2}\right)$ is the average surface area of the coupons and $t(\mathrm{~h})$ is the immersion time. The inhibitor effectiveness $(\% I)$ was estimated from equation 2 :

$$
\% I=100\left(C R_{b}-C R_{i}\right) / C R_{b}
$$

where $C R_{b}$ and $C R_{i}$ are the corrosion rates in the absence and presence of the extract, respectively. The fractional surface coverage was calculated from $\% I$ using equation 3. 


$$
\Theta=\% \mathrm{I} / 100
$$

\section{Intensifier blending}

The highest concentration of the dye extract was blended with a mixture of 2.0 wt $\% \mathrm{KI} / 1.0 \mathrm{wt} \% \mathrm{CuI}$, and the inhibition efficiency (effectiveness) of the resulting mixture was determined using the weight loss procedure above described.

\section{Solvatochromic technique}

To determine the effect of solvents on the inhibitor effectiveness, the extract with the intensifier blend was formulated in different solvents, namely water (W), methanol $(\mathrm{M})$, nitromethane $(\mathrm{N})$ and formic acid $(\mathrm{F})$. The uv/vis spectra of the lowest concentration $(1.0 \mathrm{mg} / \mathrm{L})$ of the dye, both in the acid and in the different solvents, were scanned ab initio using UNICO-UV-Spectrophotometer (Model 2010, Made in China) at a dilution of 1:40. The metal coupons were thereafter immersed in the test solutions for 5 hours before retrieval, and the absorbance and maximum wavelength of absorption of the corrosion products were also obtained. These formulations in the different solvents were also subjected to weight loss measurements, as earlier described.

\section{Adsorption studies}

The values of fractional surface coverage obtained were fitted into Langmuir, Temkin, Flory Huggins and Frumkin adsorption models, respectively, given by equations 4-7 [30-31]. These models were used to probe the responsiveness of fractional coverage on the steel surface $(\theta)$ to changes in concentrations $(C)$ of the extract.

$$
\begin{gathered}
\log (c / \theta)=\log C+\log K \\
\exp (-2 \alpha \theta)=K C \\
\log (c / \theta)=\log \mathrm{K}+x \log (1-\theta) \\
\log \left(\frac{c \theta}{1-\theta}\right)=2.303 \log K+2 \alpha \theta \\
\Delta \mathrm{G}_{a d s}=-R T \ln \left(55.5 K_{\text {eq }}\right)
\end{gathered}
$$

where $\alpha$ is the lateral interaction term or interaction parameter describing the interaction in the adsorbed layer, $x$ is the size parameter which measures the number of water molecules substituted by the inhibitor molecules, $K$ is the adsorption-desorption equilibrium constant related to the free energy of adsorption according to equation $8, R$ is the universal gas constant, and $T$ is the temperature. 


\section{Atomic Absorption Spectrophotometric (AAS) technique}

Copper ions content in the formulation was determined by Atomic Absorption Spectrophotometry using model 939/959 UNICAM Spectrophotometer with deionized water used as blank.

\section{Results and discussion}

\section{Corrosion rate and dye effectiveness}

The corrosion rates of mild steel after 5 hours of immersion in $1.0 \mathrm{M} \mathrm{HCl}$, in the absence and presence of annatto dye at $30-60{ }^{\circ} \mathrm{C}$, were calculated. Corrosion rate increased with higher temperatures, but decreased with an increase in concentration of the extracts, which agrees with findings from some other reports [31-33]. Results indicate that corrosion rate was even reduced by the addition of very low concentrations of annatto dye extract (Fig. 4).

\begin{tabular}{|c|c|c|c|c|c|c|}
\hline \multirow{6}{*}{ 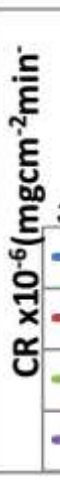 } & $\begin{array}{r}300 \\
200 \\
100 \\
0\end{array}$ & $I^{2}$ & $\pi$ & & $-\pi$ & $\begin{array}{r}-1.0 \mathrm{~W} \\
--3.0 \mathrm{~W} \\
-\quad 5.0 \mathrm{~W}\end{array}$ \\
\hline & & 303 & 313 & 323 & 333 & \multirow{5}{*}{$\mathrm{T}(\mathrm{K})$} \\
\hline & $\sim 1.0 \mathrm{~W}$ & 48 & 66 & 77 & 114 & \\
\hline & $-3.0 \mathrm{w}$ & 44 & 60 & 73 & 108 & \\
\hline & $-5.0 \mathrm{w}$ & 38 & 54 & 64 & 98 & \\
\hline & $\leftarrow$ ACID & 126 & 157 & 176 & 241 & \\
\hline
\end{tabular}

Figure 4. Variation of the corrosion rate with temperature.

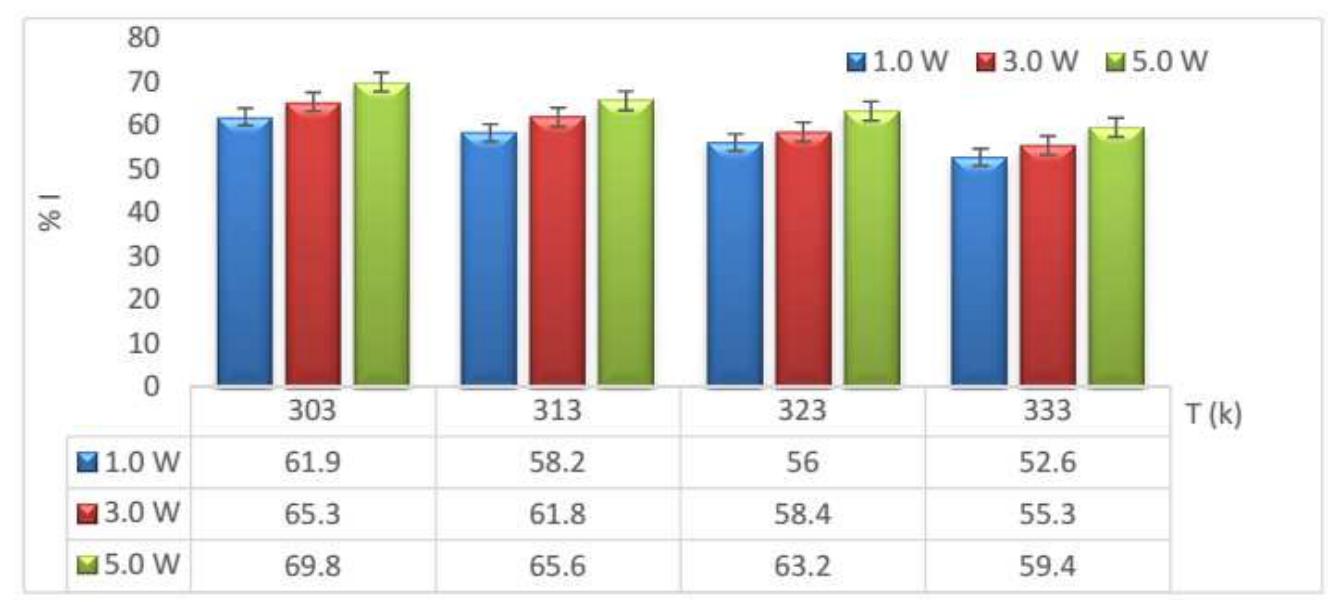

Figure 5. Variation of inhibition efficiency with concentration and temperature.

The inhibitor effectiveness (inhibition efficiency) increased with a higher concentration of the extract, and decreased as immersion system temperature increased (Fig. 5).

This effectiveness may be attributed to the presence of the electron rich phytochemicals earlier mentioned. Bixin and norbixin may be the active ingredients in the dye extract responsible for the high inhibition efficiency. The corrosion inhibition process may be due to adsorption of these phytochemicals 
onto the mild steel surface by interaction of 'phyto-electrons' from heteroatoms, and pie-functionalities of these phytochemicals with the vacant d-orbitals of iron. However, further study is recommended to help assign inhibitive effects to these phytochemicals, and elucidate their contributions.

\section{Effect of intensifier blend}

The use of plants biomass as corrosion inhibitors is limited, because they do not have long shelf life (they degrade with time), and their phyto-compounds lose their effectiveness at high temperatures [33].

In oilfields, for instance, when the borehole temperature assumes higher values due to geothermal gradient, an inhibitor with good performance at surface conditions may not protect the steel structures in the deep. An intensifier (sometimes called an inhibitor aid) [34] is usually added to enhance the performance of the inhibitor at high temperatures and long exposure time [33]. Potassium iodide has been widely reported to elicit synergistic effect to inhibitors in deep sour wells [35-36]. Attempts were made to blend the extract with 2.0 wt $\% \mathrm{KI} / 1.0 \mathrm{wt} \% \mathrm{CuI}$. Results revealed that $\mathrm{KI} / \mathrm{CuI}$ blend intensified the effectiveness of the extract, even at temperatures up to $90{ }^{\circ} \mathrm{C}$ (Table 1). This intensifying effect may be due to production or release of metal ions which form coordinated or associated complexes with some of the phyto-compounds in the dye, leading to formation of protective deposits (film) on the metal surface [37].

Table 1. Inhibition effectiveness of annatto dye in the presence of blend of $\mathrm{KI} / \mathrm{CuI}$ and different solvents.

\begin{tabular}{lcccccc}
\hline \multicolumn{1}{c}{$\mathbf{T}\left({ }^{\mathbf{0}} \mathbf{C}\right)$} & $\mathbf{3 0}$ & $\mathbf{4 0}$ & $\mathbf{5 0}$ & $\mathbf{6 0}$ & $\mathbf{7 5}$ & $\mathbf{9 0}$ \\
\hline Dye alone & 69.8 & 65.6 & 63.2 & 59.4 & 38.3 & 21.4 \\
Dye+KI/CuI alone & 92.4 & 85.8 & 77.9 & 68.5 & 59.2 & 53.6 \\
Formic acid CIF & 87,9 & 82.3 & 76.1 & 62.9 & 55.3 & 48.6 \\
Methanol CIF & 93.6 & 86.8 & 78.6 & 69.1 & 60.8 & 55.4 \\
Nitromethane CIF & 95.4 & 89.2 & 80.1 & 72.3 & 61.4 & 56.9 \\
\hline
\end{tabular}

\section{Effect of solvents}

A study was designed to determine the effect of some polar solvents on the inhibition effectiveness of the dye extract. It has been claimed that solvents function by either reducing the viscosity for ease of handling or ensuring the stability of the corrosion inhibitor formulation in various environments [33]. The effect of extracting solvents on inhibitor effectiveness has been described [19], but researchers are yet to quantitatively describe the effect of the solvent or cosolvent used in corrosion inhibitor formulation on its effectiveness. When a corrosion inhibitor is blended with intensifier(s) and a solvent (and sometimes with a surfactant) and co-solvent, the resulting mixture is usually called corrosion inhibitor formulation (CIF). The purpose of a solvent may sometimes be similar to that of a surfactant, but with a different mechanism, i.e., to improve CIF solubility, dispersability in the acid and wettability on the acid-steel interface [33]. Solvents with polarity (methanol, nitromethane and formic acid) were selected (concentration $0.8 \mathrm{wt} \%$ and consisting of $50 \%$ by volume of the total test solution) to promote miscibility and to enhance inhibition effectiveness. 
Results show that the solvents affected the inhibition efficiency of the formulation. The effectiveness increased in methanol and nitomethane, but decreased in formic acid (see Table 1). Nitromethane showed higher enhanced effectiveness than methanol, and this may be explained in terms of the higher number of electron rich atoms $(\mathrm{N}$ and $\mathrm{O})$ in it than in ethanol. Formic acid may be thought to act as antagonistic to the corrosion inhibition or even aiding to increase the corrosion rate of the system. For practical applications, methanol is more cost effective than nitromethane, but may be hazardous to health like formic acid.

\section{Solvent effect on uv/vis absorption}

In order to elucidate the effect of solvents on the adsorption of the dye molecules onto the metal surface, the uv/vis absorbance spectra of the dye in the various solvents were obtained before and after the immersion of steel. Before immersion, the dye sample showed absorbance of 1.889 (dye in water), 0.622 (in methanol), 0.646 (in formic acid) and 1.258 (in nitromethane). One wonders why the absorbance values in the different solvents were lower than those obtained in water (Table 2). Introduction of the solvents lowered the absorbance of the dye molecules, but after the adsorption process, increase in absorbance was observed with nitromethane (1.274) and methanol (1.031), while formic acid (0.610) showed a decrease (Table 2).

Table 2. Absorbance (A) and maximum wavelength of absorption $\left(\lambda_{\max }\right)$ of dye extract of annatto in different solvents before and after adsorption on mild steel in $1.0 \mathrm{M}$ hydrochloric acid.

\begin{tabular}{lllll}
\hline System & \multicolumn{2}{c}{ A } & \multicolumn{2}{c}{$\boldsymbol{\lambda}_{\text {max }}$} \\
\cline { 2 - 5 } & $\begin{array}{l}\text { Before } \\
\text { immersion }\end{array}$ & $\begin{array}{l}\text { After } \\
\text { immersion }\end{array}$ & $\begin{array}{l}\text { Before } \\
\text { immersion }\end{array}$ & $\begin{array}{l}\text { After } \\
\text { immersion }\end{array}$ \\
\hline CIF in water & $1.991,1.899$ & $1.552,1.179$ & 249,371 & 250,371 \\
CIF in formic acid & 0.646 & 0.610 & 371 & 370 \\
CIF in methanol & 0.622 & 1.031 & 371 & 369 \\
CIF in nitromethane & 1.258 & 1.274 & 349 & 337 \\
\hline
\end{tabular}

The differences in absorbance before and after adsorption may be attributed to synergistic enhancement offered by the solvents. The mechanism underlying the observed phenomena is still unclear, although it appears consistent with the trend of solvent effect on the inhibition efficiencies (Table 1). It is believed that the complex(es) formed between $\mathrm{Fe}^{2+}$ and phyto-compounds in dye was/were rapidly dissolved by formic acid, thus reducing the absorbance. Further studies may be needed to understand this mechanism. In addition, shifts to shorter wavelengths of absorption were also observed in all the solvents after the adsorption process (Table 2).

\section{Mechanism of inhibition}

The fractional surface coverage $(\theta)$ data were fitted into the adsorption models described above by a plot of some functions of $\theta$ against those of the inhibitor's concentration (C). The best fit was obtained with the Temkin adsorption model $\left(\mathrm{R}^{2}>0.96\right)$ (Fig. 6), the linear form of which is given in equation 9: 


$$
\theta=-0.5 \alpha(\ln K+\ln C)
$$

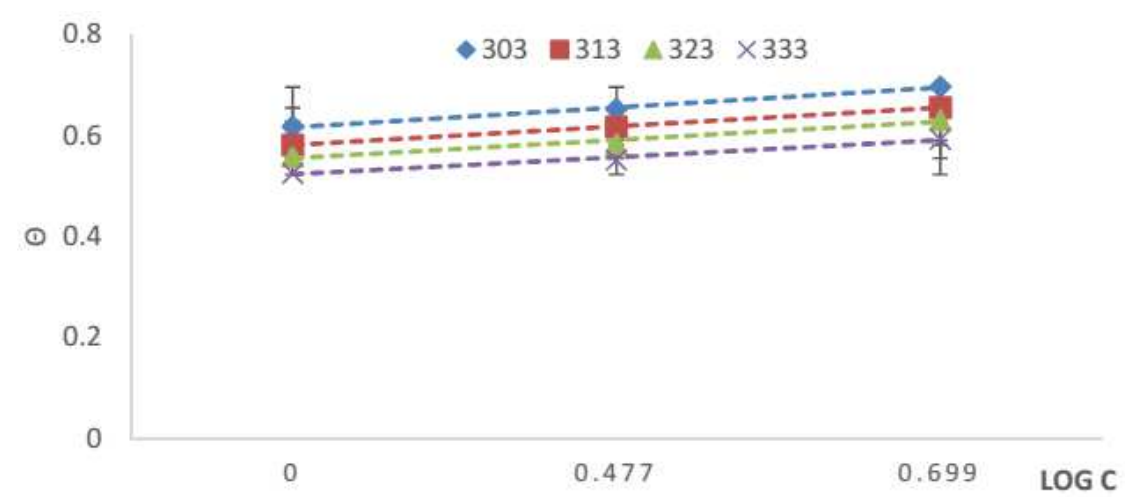

Figure 6. Temkin adsorption isotherm for the inhibition of mild steel corrosion by different concentrations of annatto dye extracts at different temperatures.

Negative values of $\Delta \mathrm{G}_{a d s}$ were obtained at all temperatures studied (Table 3), which implies spontaneous adsorption. It has been established that when $\Delta \mathrm{G}_{a d s}$ is less negative than $-20 \mathrm{~kJ} / \mathrm{mol}$, the mechanism is physical adsorption, and if it is more negative than $-40 \mathrm{~kJ} / \mathrm{mol}$, it is chemical adsorption $[30,33]$.

Table 3. Parameters deduced from Temkin adsorption isotherm.

\begin{tabular}{cccc}
\hline Temperature & $\boldsymbol{\alpha}$ & $\mathbf{K}_{a d s} \mathbf{x} \mathbf{1 0}^{\mathbf{1 4}}$ & $\boldsymbol{\Delta} \mathbf{G}_{\text {ads }}(\mathbf{k J} / \mathbf{m o l})$ \\
\hline 303 & 0.039 & 1.91 & -93.25 \\
313 & 0.037 & 5.04 & -95.69 \\
323 & 0.036 & 2.78 & -94.19 \\
333 & 0.034 & 2.41 & -93.83 \\
\hline
\end{tabular}

Physical adsorption mechanism (physisorption) is usually associated with intermolecular forces which would cause preferential binding of certain phytochemicals of the dye to the metal (reversible with an increase in temperature), while chemical adsorption involves chemical bond formation (coordinate covalent in nature), usually with the release of heat. However, the obtained $\Delta \mathrm{G}_{a d s}$ values indicate chemisorption which may be further supported by the exothermicity of the process and large values of $\mathrm{K}_{e q}$. Chemisorption is associated with monolayer adsorption and protective film formation. However, this observation is not in agreement with the predictions usually made from the trend of inhibition efficiency with temperature. When inhibition efficiency decreases with higher temperatures, as the ones obtained in this study, physical adsorption mechanism is usually proposed, which involves multilayer adsorption. The values of obtained $\alpha$ and $K_{e q}$ signify strong adsorbate-adsorbent molecular attraction and great binding strength.

\section{Thermodynamic considerations}

Energetically, the obtained negative $\Delta \mathrm{G}_{a d s}$ is consistent with the spontaneous nature of the adsorption processes. A classical thermodynamic model called the transition state equation (equation 10) was used to deduce some energetic parameters (Table 4) associated with the adsorption process: 


$$
\mathrm{CR}=(\mathrm{RT} / \mathrm{Nh}) \exp \left(\Delta \mathrm{S}_{a d s} / \mathrm{R}\right) \exp \left(\Delta \mathrm{H}_{a d s} / \mathrm{RT}\right)
$$

where $C R$ is the corrosion rate, $\mathrm{h}$ is Plank's constant, $\mathrm{N}$ is Avogadro's number, $\mathrm{R}$ is the universal gas constant and $\mathrm{T}$ is the absolute temperature. A plot of log $\mathrm{CR} / \mathrm{T}$ against $1 / \mathrm{T}$ (not shown) afforded straight lines with slopes $\left(\Delta \mathrm{H}_{a d s} / 2.303 \mathrm{R}\right)$ and intercepts $\left[\log (\mathrm{R} / \mathrm{Nh})+\left(\Delta \mathrm{S}_{a d s} / 2.303 \mathrm{R}\right)\right]$. Obtained data reveal that the adsorption process was exothermic, and with a higher heat of adsorption in the presence of the extracts. Obtained negative $\Delta \mathrm{S}_{a d s}$ values indicate a decrease in entropy, and consequently, an increased orderliness in the system, probably brought about by the reduction in the number of molecules of the active constituents of the extracts in the bulk solution, due to adsorption [32]. The decrease in orderliness was not concentration dependent, and may have resulted from the loss of heat to the surroundings.

Table 4. Kinetic and thermodynamic parameters.

\begin{tabular}{lcccc}
\hline System & $\mathbf{A}\left(\mathbf{x 1 0}^{-\mathbf{5}}\right)$ & $\mathbf{E}_{\mathbf{a}}(\mathbf{k J} / \mathbf{m o l})$ & $\mathbf{\Delta} \mathbf{H}(\mathbf{k J} / \mathbf{m o l})$ & $\boldsymbol{\Delta} \mathbf{S}\left(\mathbf{x 1 0} \mathbf{1 1}^{\mathbf{1 1}} \mathbf{J} / \mathbf{m o l}\right)$ \\
\hline Blank & 1.05 & 1.65 & -1.44 & -3.83 \\
$\mathbf{1 . 0} \mathbf{~ m g} / \mathbf{L}$ & 3.55 & 2.22 & -0.88 & -3.83 \\
$\mathbf{3 . 0} \mathbf{~ m g} / \mathbf{L}$ & 3.23 & 2.37 & -2.09 & -3.83 \\
$\mathbf{5 . 0} \mathbf{~} \mathbf{L} / \mathbf{L}$ & 2.28 & 2.89 & -2.24 & -3.83 \\
\hline
\end{tabular}

\section{Kinetic considerations}

The percentage inhibition effectiveness decreased with higher temperatures for all the studied concentrations of the extracts, which means a possible shift in adsorption-desorption equilibrium towards desorption process, as temperature increases. This agrees with Le Chatellier's principle, which describes shifts in equilibrium position to annul the effects of changes in equilibrium conditions. However, the introduction of the intensifier blend elicited enhanced effectiveness on the extract, even when temperature increased to $90{ }^{\circ} \mathrm{C}$. Corrosion rate data obtained from this study were also fitted into Arrhenius kinetic model (equation 11), to elucidate the effect of temperature on the inhibition efficiency and adsorption behaviour of the extracts.

$$
\mathrm{K}=\mathrm{A} \exp (-\mathrm{Ea} / \mathrm{RT})
$$

Activation energy $\left(\mathrm{E}_{\mathrm{a}}\right)$ was deduced from Arrhenius plot of $\log C R$ against the reciprocal of temperature. In accordance with the concept of activation, the acid molecules must acquire sufficient energy to overcome a minimum energy barrier $\left(E_{\mathrm{a}}\right)$, required to collide, attack and dissolve the steel in the aqueous medium. The $E_{a}$ values of the inhibited solutions are larger than those of the free acid solution, which implies that the inhibited acid molecules must pass over a higher energy barrier to corrode the metal. Acid molecules that are unable to acquire this higher energy become deactivated, which promotes inhibition (protection) of the metal corrosion. 


\section{Health, safety and environmental considerations}

Since heavy metals are known to be toxic, the amount of copper ions present in the inhibitor was evaluated in terms of its friendliness, or otherwise. Copper does not break down in the environment. Its accumulation in water may have slight effects on biodiversity, in case of exposure. The amount of copper obtained from AAS measurement was $1.02 \pm 0.11 \mu \mathrm{g}$. This value falls within the Recommended Dietary Allowance and Tolerable Upper Intake Level provided by both EPA and WHO. Based on this result, it is believed that the corrosion inhibitor formulation will be safe to the environment and people, if applied in the industry.

\section{Conclusions}

Based on the results obtained from this study, it may be concluded that extract of annatto is an effective corrosion inhibitor for mild steel in $1.0 \mathrm{M} \mathrm{HCl}$ at 30-60 ${ }^{\circ} \mathrm{C}$. Addition of $\mathrm{HI} / \mathrm{CuI}$ blend to the extract synergistically improves the effectiveness of the inhibitor, even at temperatures up to $90{ }^{\circ} \mathrm{C}$. The performance of the corrosion inhibitor formulation is affected by the solvents used. The absorption maxima and absorbance of the formulations were shifted in the solvents from values in water. The formulation functions by spontaneous adsorption of its phyto-compounds on the steel surface with the evolution of heat. The formulation can serve as a cheap and non-toxic alternative for chemical dyes used as inhibitors.

\section{Acknowledgements}

The authors are grateful to the World Bank and African Centre of Excellence in Oilfield Chemicals Research, as well as to Ubong Jerome Etim and Eka-Eric Johnson Idang, for their assistance/contributions.

\section{References}

1. Otaibi MS, Al-Mayouf AM, Mousa AA, et al. Arab J Chem. 2014;7:340346.

2. Sangeetha M, Rajendran S, Muthumegala TS, et al. Zast Mater. 2011;52:319.

3. Satapathy AK, Gunasekaran G, Sahoo SC, et al. Corros Sci. 2009;51:28482856.

4. Quraishi MA, Singh A, Singh VK, et al. Mater Chem Phys. 2010;122:114122.

5. Deyab MAJ. Taiwan Inst Chem Eng. 2015;51:1-6.

6. Bammou L, Belkaouda M, Salghi R, et al. J Assoc Arabs Bas Appl Sci. 2014,16:83-90

7. Shabani-Nooshabadi M, Ghandchi MS. J Ind Eng Chem. 2015;31:213-237.

8. Kajeswari V, Kesavan D, Gopiraman M, et al. Appl Surf Sci. 2014;314:537-545.

9. Bhawsar J, Jain PK, Jain P. Alexand Eng J. 2015;54:769-775.

10. Hu Q, Qiu Y, Zhang Q, et al. Chin J Chem Engin. 2015;23:1408-1415. 
11. Mehdipour M, Ramezanzadeh B, Aman SY. J Ind Eng Chem. 2015;21:318327.

12. Kumar CBP, Mohama KN. Egyp J Petrol. 2014;23:201-211.

13. Abdel-Gabber AM, Abd-El-Nabey BA, Sidahmed AM, et al. Corros Sci. 2006;49:2765-2779.

14. Soltani N, Tavakkoli N, Khayatkashani M, et al. J Ind Eng Chem. 2014;20:3217-3227.

15. Odewunmi NA, Umoren SA, Gasem ZM, et al. J Taiwan Inst Chem Eng. 2015;51:177-185.

16. Obi-Egbedi NO, Obot IB, Umoren SA. Arab J Chem. 2012;5:361-373.

17. Bouknana D, Hammouti B, Messali M, et al. Asian Pacif J Trop Disea. 2014;4:5963-5974.

18. Deyab MA. J Ind Eng Chem. 2015;22:384-389.

19. Umoren SA, Solomon MM, Eduok UM, et al. J Environ Chem Engin. 2014;2:1048-1060.

20. Khadom AA, Hassan AF, Abod BM. Proc Saf Environ Protect. 2015;98:93101.

21. Singh A, Lin Y, Ebenso EE, et al. J Ind Eng Chem. 2015;24:219-228.

22. Ganju K, Ganju EJ. Medic Pharm Innov. 2014;1:21-24.

23. Reith JF, Gielen JW. J Food Sci. 1971;36:861-864.

24. Silva GF, Gamarra FM, Oliveira AL, et al. Brazil J Chem Eng. 2008;25:419-426.

25. Vilar DA, Vilar MS, Moura TF, et al. Scientific World J. 2014; Article ID 857292.

26. Tamil SA, Dinesa MG, Satyan RS, et al. J Appl Pharm Sci. 2011;1:116120.

27. Ebenso EE, Oguze EE. Mater Let. 2005;59:2163-2165

28. Oguzie EE, Njoku VO, Enenebeaku CK, et al. Corros Sci. 2008;50:34803486.

29. Oguzie EE, Okulue BN, Ebenso EE, et al. Mater Chem Phys. 2004;87:394400.

30. Nwabanne JT, Okafor JNJ. Min Mater Charact Engin. 2012;11:885-890.

31. Geethanjali R, Subhashini S. Port Electrochim Acta. 2015;33:35-48.

32. Odozi NW, Babalola JO, Ituen EB, et al. J Phys Chem. 2015;4:1-9.

33. Ituen EB, Essien EA, Udo UE, et al. Adv Appl Sci Resear. 2015;5:26-53.

34. Finsgar M, Jackson J. Corros Sci. 2014;8:17-41.

35. Hill DG, Jones A. Corros. 2003;No. 03121.

36. Quraishi MA, Sardar N, Ali H. Corros. 2002;58:317-321.

37. Deyab MA. Corros Sci. 2007;49:2315-2328.

38. Williams DA, Holifield PK, Looney JR, et al. Inhibited Acid System for Acidizing Wells. US Patent 5,209,859, Exxon Chemical Patents, Inc: Linden, New Jersey; 1993. 